\title{
Cover Memo: Volume 18, Issue 4, Special Issue on Intersectional Science Policy
}

\section{Emily Pinckney}

Executive Director, 500 women scientists

\section{Tiffany G. Harrison}

Director, Public Policy Special Interest Group, National Society of Black Engineers (NSBE)

\section{Pamela A. Padilla}

President, Society for Advancement of Chicanos/Hispanics and Native Americans in Science (SACNAS) https://doi.org/10.38126/ISPG1804CM

This Special Issue of the Journal of Science Policy \& Governance has been produced in partnership with Society for Advancement of Chicanos/Hispanics and Native Americans in Science (SACNAS), 500 Women Scientists and the National Society of Black Engineers (NSBE) and is sponsored by the National Science Policy Network (NSPN).

Seventy-five years ago, Vannevar Bush launched a new vision of science as a public good in the U.S., essential to the welfare and future of humanity. Yet even as scientific discovery has progressed, its rewards and successes have been limited by a failure to consider science's intersection with diversity, equity, inclusion, and social justice.

Today, scientific funding is not distributed equally, but is biased toward certain types of researchers, institutions, regions, and special interests. For instance, grant and award processes consistently undersupport researchers who are early-career and/or from marginalized communities. Awards skew away from rural institutions and low-growth regions, and ignore important issues, such as women's reproductive health. Research grants and contracts are essential for an institution's long-term viability, reducing tuition dependence and providing important funding for society-shaping innovations. It is time to address funding disparities perpetuated by bias through elevating and supporting the work of those from communities that have been historically underrepresented.

Data and research indicate that true diversity in the Science, Technology, Engineering, and Mathematics (STEM) workforce not only creates fertile ground for transformative research to flourish, but also garners financial returns to industry and business. As such, diversity is a determining factor for the competitiveness of the United States STEM workforce and a catalyst for innovation that often leads to breakthroughs. Our organizations know that to progress in science, we must represent all intersections of diversity in scientific effort and knowledge. A diverse STEM workforce also has the benefit of addressing health disparities faced by underserved communities that disproportionately impact people of color or women.

Scientific practice constructed without attention to issues of equity and inclusion will neglect and harm disenfranchised populations. Articles in this special issue explore how under-representation of people of color in medical education has resulted in greater mortality from skin cancer, how historical methodologies for studying vehicle safety have meant greater casualties amongst those with average or heavy weight 
female body types, and how bias in algorithms can restrict access to fair housing and lending for minorities. Without an equitable and inclusive lens, implicit bias and discrimination will continue to persist in research structures.

As we look to science to inform decision-making and improve governance, we must also include research in support of social and environmental justice. In this issue, many of the concerns raised and addressed have been uncovered or informed by thoughtful, inclusive research. As such, remote sensing and analysis of public health data has helped identify that communities of color and with lower incomes are disproportionately harmed by urban heat and asthma. Social and economic studies can tangibly improve outcomes in communities experiencing opioid crisis or gentrification.

In this issue, we look not only forward but also back, at the barriers created by undervaluing diversity, equity, inclusion, and justice in science and policy. In 1945, Vannevar Bush warned that "science can be effective in the national welfare only as a member of a team." We believe that science must serve society by being open, inclusive and accessible. We invite you to read the sixteen policy memos in this Special Issue, and carefully consider how these opportunities can guide your future research, development, and activism.

Emily Pinckney, Executive Director, 500 Women Scientists

Tiffany G. Harrison, Director, Public Policy Special Interest Group, National Society of Black Engineers (NSBE)

Dr. Pamela A. Padilla, President, Society for Advancement of Chicanos/Hispanics and Native Americans in Science (SACNAS)

Emily Pinckney is the Executive Director of 500 women scientists, an organization committed to speaking up for science and for marginalized communities in science, as well as confronting the shameful history of science being used to harm people - and the participation of the scientific community in this harm. Although she was involved in volunteerism early in her youth, her experiences as a queer black female scientist led her to focus her efforts on teaching environmental justice principles and equity as well as educate underserved communities on how to navigate around systemic barriers to community-based environmental decisionmaking. Youth involvement and education has been the focus of her work. She currently serves on the WA state Environmental Justice Task Force, Sustainable Tacoma Commission, the Diversity Equity Inclusion Community of Practice (DEICOP), and the South Sound Urban League Young Professionals. Emily is trained as a marine biologist and works as the Community Outreach Educator for the Seattle Aquarium.

Tiffany G. Harrison is the Director of the Public Policy Special Interest Group (SIG) for the National Society of Black Engineers, whose mission is to study, discuss, educate, and advise on public policy issues affecting Black engineers and scientists in academia, industry, government, and public communities. SIG seeks to affect positive change as a Society in STEM-related policies in education, the workforce, and the world. Outside of the SIG, she has served as the Region 6 Professional Development Chair, Membership Chair and has been a SEEK (Summer Engineering Experience for Kids) Mentor for San Diego and Sacramento. As a former City of San Diego Human Relations Commissioner, she also worked with local stakeholders to support SEEK operations in San Diego and share the work of NSBE with the commission. Outside of NSBE, she works for the Honorable Councilmember Montgomery Steppe as a staffer that provides resources and assistance to communities in the district and also advises on parks, health, education and workforce development policy and initiatives. 
Pamela A. Padilla is the President of Society for Advancement of Chicanos/Hispanics and Native Americans in Science (SACNAS), which is dedicated to fostering the success of Chicanos/Hispanics and Native Americans, from college students to professionals, in attaining advanced degrees, careers and positions of leadership in STEM. Through her work with the SACNAS, she was awarded an NIH training grant that supports STEM diversity training across the nation. She obtained her Ph.D. from the University of New Mexico and was a National Science Foundation Postdoctoral Fellow at the Fred Hutchinson Cancer Research Center where she discovered regulatory mechanisms involved with stress responses and hypometabolic states. As an Associate Vice President of Research and Innovation and former Associate Dean of Research and Graduate Studies, she is deeply involved with and committed to efficient research administration, effective program management, sound operations, fiscal responsibility, collaborative leadership, building partnerships, compliance and integrity, student training, and STEM diversity initiatives. As an academic administrator, she strives to support facilities and partnerships that propel faculty research, values research within many fields, and has a great interest in serving a Hispanic Serving Institute. In particular, Padilla has provided programs and mentorship to engage early career faculty with research development opportunities. 